\title{
TSUNAMI RESILIENT COMMUNITIES
}

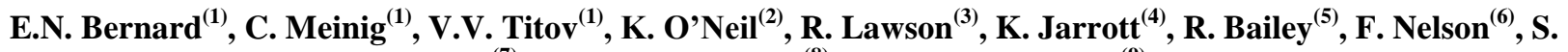 \\ Tinti $^{(7)}$, C. von Hillebrandt ${ }^{(8)}$, and P. Koltermann ${ }^{(9)}$ \\ ${ }^{(1)}$ NOAA/Pacific Marine Environmental Laboratory, 7600 Sand Point Way NE Seattle, Washington, 98115 USA, \\ Email:eddie.n.bernard@noaa.gov ; christian.meinig@noaa.gov; vasily.titov@noaa.gov \\ ${ }^{(2)}$ NOAA/ National Data Buoy Center, 1007 Balch Blvd., Stennis Space Center, MS 39529, \\ Email: kathleen.oneil@noaa.gov \\ ${ }^{(3)}$ SAIC, 4065 Hancock Street, San Diego, CA 92110, Email: lawsonra@ saic.com \\ ${ }^{(4)}$ Australian Bureau of Meteorology, JCOMM, 700 Collins Street, Docklands, GPO Box 1289, Melbourne VIC 3001, \\ AUSTRALIA, Email: k.jarrott@bom.gov.au \\ ${ }^{(5)}$ Australian Bureau of Meteorology, IGC-IOTWS, 700 Collins Street, Docklands, GPO Box 1289, Melbourne VIC \\ 3001, AUSTRALIA, Email: r.bailey@bom.gov.au \\ ${ }^{(6)}$ Samoa Disaster Management Office, Ministry of Natural Resources and Environment, Apia, SAMOA, \\ Email: filomena.nelson@mnre.gov.ws \\ ${ }^{(7)}$ University of Bologna, IGC- NEAMTWS, Dipartimento di Fisica, Viale Carlo Berti Pichat, 8, I-40127 Bologna, \\ ITALY, Email: steve@ibogfs.df.unibo.it \\ ${ }^{(8)}$ University of Puerto Rico, Puerto Rico Seismic Network, PO Box 9017, Mayaguez, PUERTO RICO, \\ Email: christa@prsn.uprm.edu \\ ${ }^{(9)}$ Intergovernmental Oceanographic Commission of UNESCO, 1 rue Miollis, Paris Cedex 15 75732, FRANCE, Email: \\ p.koltermann@unesco.org
}

\begin{abstract}
A tsunami resilient community is prepared for, and properly responds to, the next tsunami to minimize loss of life and disruption to normal community activities. Key technical elements required to create resilience are evacuation plans, based on tsunami hazard maps, and accurate real-time tsunami forecasts. To produce tsunami evacuation maps requires an assessment of the tsunami hazard from historical evidence or plausible scenarios. To accurately forecast tsunamis in real time requires timely ocean observations from deep-ocean and coastal sea level sensors to generate and disseminate warning and forecast information before the tsunami strikes. Deep-ocean tsunami data, from instruments termed tsunameters, and coastal sea level data, from tide gauges, are assimilated into high-resolution forecast models to provide an accurate forecast of tsunami flooding at specific sites. Presently, there are about 50 deep ocean and 200 sea level stations that provide tsunami data for four regional tsunami warning systems in the Pacific and Indian Oceans and in the Caribbean and Mediterranean Seas. Real-time forecast models can also be used to generate tsunami hazard maps that lead to the production of evacuation maps to guide community resilience activities. To sustain and maintain these regional tsunami warning systems, the concept of a Tsunami Forecasting Framework is introduced as a way to encourage standardization of modeling and observational technologies, to provide a testing environment for introducing and accepting improved technologies, and to encourage scientific engagement through opportunities for research. Future challenges are portrayed as the reality of sustaining tsunami warning
\end{abstract}

systems between destructive tsunamis. Proactive ways a region can support an effective regional tsunami warning system include the creation of a tsunami response and recovery plan that would not only save lives during the hours of tsunami attack, but would save communities during the years of recovery.

\section{REVIEW OF RECENT PROGRESS IN TSUNAMI RESILIENCE THROUGH REGIONAL TSUNAMI WARNING AND MITIGATION SYSTEMS}

\subsection{Introduction}

The greatest challenge facing tsunami research and mitigation specialists is to change the perception that tsunamis are rare events. Data clearly show that every year a damaging tsunami will cause death and destruction somewhere along our global coastlines. For example, following the catastrophic 2004 Indian Ocean tsunami, which killed an estimated 230,000 people, there have been five tsunamis: 2005 (Sumatra), 2006 (Java), 2007 (Solomon Islands), 2009 (Samoa), and 2010 (Chile) that killed over 1000 people. The concept of a tsunami-resilient coastal community is a proactive way to change attitudes from "tsunamis will not affect our community" to "preparing for the next tsunami." Elements of a tsunami-resilient community include: hazard assessment, community preparedness, and warning guidance [1].

\subsection{Hazard Assessment}

To prepare a tsunami-prone or potentially impacted community for the next tsunami, the community needs 
to first identify the possible extent of hazard by examining the written/oral and, where appropriate, geological history of the community. In addition, plausible scenarios need to be applied to determine the areas at risk from tsunami flooding. Because numerical models are used to simulate the potential flooding risks and public safety of any community, modeling standards are desirable. Coastal communities are under constant physical development that alters the coastline position, bathymetry, and topography. Such physical changes in the coastline affect the accuracy of the determination of hazardous areas. Using standard and benchmarked numerical models provides some assurance that the latest version of the hydrodynamic model represents responsible science. The tsunami modeling community established a Working Group under the Intergovernmental Coordination Group for the Indian Ocean Tsunami Warning and Mitigation System (ICG/IOTWS) and held a series of workshops to benchmark tsunami models. One of the inundation models that performed well in these benchmark experiments has been selected by the IOTWS as one of the standard models for use in developing evacuation maps for coastal communities [2].

\subsection{Community Preparedness}

Coastal communities and national governments must accept responsibility for preparing for the next tsunami. One of the most effective approaches to communitybased preparedness is to identify a community advocate(s) who will become the champion(s) for tsunami preparedness [3]. Advocates must work closely with community leaders to ensure that planned activities are properly followed and integrated within multihazard frameworks. Several examples from past tsunamis indicate that communities with tsunami advocates, who educated their community about the dangers of tsunami, can significantly reduce fatalities. In 1993, Japan experienced a local tsunami that killed about $15 \%$ of the exposed population on Okushiri Island. A similar tsunami occurred in Papua New Guinea in 1998 that killed $60 \%$ of the residents in a small village. The difference was that the Japanese people were educated about tsunamis and knew how to respond to the shaking of an earthquake, while the people in New Guinea did not. A more recent example was the 2004 Sumatra tsunami, where the indigenous inhabitants of Simeulue Island, Indonesia, knew to flee to high ground upon feeling the strong shaking from a large earthquake [4].

Educational tools are available to support community advocates to develop community awareness and preparedness, but an educational plan needs to be developed and implemented in tsunami-prone communities to save lives in the future. The advocates also need access to the products of the best science available and sources of tsunami warning information. Community awareness and preparedness working groups have been established by the Intergovernmental Coordination Groups (ICGs) of the four regional tsunami warning systems to share experiences and promote best practices. Additionally, the installation and maintenance of tsunami measurement instruments for both the deep-ocean and coastal areas offer technologies for teaching the community about tsunamis through visible evidence that tsunamis strike their shoreline.

\subsection{Warning Guidance}

To mobilize the tsunami-resilient community into action to escape approaching tsunamis, residents and visitors must know the physical signs of tsunami danger (ground shaking, rapid withdrawal of the ocean, or loud roar from the ocean). Unfortunately, the lead time for locally generated tsunamis ( $<15 \mathrm{~min}$ ) is often too short for the technically enabled warning systems to detect and warn against the first wave. For these cases, education is the most effective tool for the tsunami-resilient community. Tsunamis, however, consist of multiple waves lasting up to several hours. Warning systems play a role in quickly determining if the earthquake had generated a tsunami, allowing coastal populations to either remain evacuated or return to normal activities. So both education and warning technology are required for local tsunamis.

For the "all clear" declaration and warning for distant tsunamis, the tsunami-resilient community must rely on warning guidance from regional warning providers. The Pacific Tsunami Warning \& Mitigation System (PTWS) has been supplying warning and mitigation services for more than 45 years through the U.S.-operated Pacific Tsunami Warning Center (PTWC). Following the 2004 Indian Ocean tsunami the United Nations established the ICG/IOTWS to develop a warning system for the Indian Ocean. To fill the immediate need, an interim advisory service has been provided by both Japan and the United States since March 2005. This service is primarily based on earthquake source and tsunami travel time information, which does not provide specific height and potential impact information.

The emergent IOTWS (IOC Technical Report \#81) is modeled after the national U.S. system, which uses data from deep-ocean tsunami detectors (tsunameters) assimilated into numerical forecast models to forecast the real-time impact of the tsunami at specific coastal communities. The new IOTWS is due to take over from the interim services in 2010, with coordinated regional tsunami watches initially being provided by India, Indonesia, and Australia. The warning systems for the other basins (including the Pacific) are also looking to introduce warning systems that provide more specific 
threat information like the IOTWS over the next 2-3 years.

An expanded network of over 50 tsunameters has been deployed in the last 3-4 years by five nations in the Indian, Pacific, and Atlantic oceans to support the more accurate forecast of tsunamis for the world's oceans. Since 2003, this method has been used to forecast tsunamis at specific harbors for 14 different tsunamis in the Pacific and Indian Oceans [5]. These forecasts have also contributed to early cancelation of distant and local warnings by measuring a non-destructive tsunami in the deep ocean near the source and relaying these data to warning centers in real time. The State of Hawaii avoided the $\$ 200,000,000$ cost of three unnecessary evacuations in 2003, 2006, and 2009 using forecasts from these new technologies.

Support for the existing deep-ocean and coastal observational networks are provided by numerous contributors coordinated through the International Oceanographic Commission (IOC). The network of deep-ocean tsunameters, created following the devastating 2004 Indian Ocean tsunami, is coordinated by an ad hoc group of nations and suppliers, named the International Tsunameter Partnership (ITP). The Partnership was formed to set guidelines for the manufacture and operations of these new instruments. The Global Sea Level Observing System (GLOSS) aims at the establishment of high-quality global and regional sea level networks for application to climate, oceanographic, and coastal sea level research. GLOSS is an international program conducted under the auspices of the Joint Technical Commission for Oceanography and Marine Meteorology (JCOMM) of the World Meteorological Organization (WMO) and IOC [6].

The IOC has established groups to set standards for deep-ocean and coastal measurements of tsunamis and communications protocol to transmit these data to appropriate tsunami warning centers [7]. These warning centers must also standardize the warning messages so that the communities understand the situation and take appropriate action.

The forecasting capability, however, is only useful if the community receives the information in a reliable and timely way and then has the knowledge to turn that information into life-saving actions or avoidance of an unnecessary evacuation. The responsibility and authority for receiving and disseminating the warning information varies from country to country, but the tsunami-resilient community accepts the responsibility by implementing ongoing training and education, redundant warning methodologies, and taking appropriate action. The community tsunami advocate serves as the daily interface between the originator of the warning guidance and local leaders of the community to be warned. This responsibility includes understanding the warning operations and communication links and interpretation of the warning information so that the community takes the appropriate action.

\subsection{Ocean Observations 2009}

As part of the OceanObs 2009 proceedings, this paper will describe the oceanographic operations of the four regional tsunami warning and mitigation systems that support resilient activities at the local level. Among the present set of challenges are the efforts to ensure that the four regions are compatible in data collection, analysis, and dissemination of warning products to ensure the public's trust and safety. Compatibility is critical in providing consistent warning and mitigation products across the globe to avoid confusion by residents as well as visitors. Since most of the world's public enjoys visiting the beautiful beaches and shorelines of the world's oceans, we must raise awareness of tsunami hazards. Each region is at a different stage of development, fiscal stability, and effectiveness. Despite these challenges, we offer a framework that will make technical standards easier to establish and sustain. With standards helping to make each region compatible with each other, this framework will eventually lead to fewer casualties and less community disruption from future tsunamis. Since a major problem following the 2004 tsunami was lack of recovery planning in the midst of the generous charitable offerings from the world, we recognize that future improvements are measured by the success of communities to not only plan for tsunamis, but to plan for recovery as well.

\section{REGIONAL TSUNAMI WARNING SYSTEMS} (FIG. 1)

In the Pacific Ocean, where roughly $60 \%$ of all tsunamis take place, the Intergovernmental Oceanographic Commission (IOC) established a Tsunami Warning System (TWS) in 1965 which has been successfully operating for more than 45 years and ensuring that people living on the ocean's rim receive prompt forecasts and warnings of impending distant tsunamis. This fully operational system has proven itself to be effective.

Following the undersea earthquake on 26 December 2004 and the subsequent strongest tsunami in recorded history, IOC took the lead in coordinating activities and immediate action to establish a Tsunami Warning System (TWS) in the Indian Ocean. The response included the establishment of interim tsunami advisories provided through the Pacific Tsunami Warning Center 


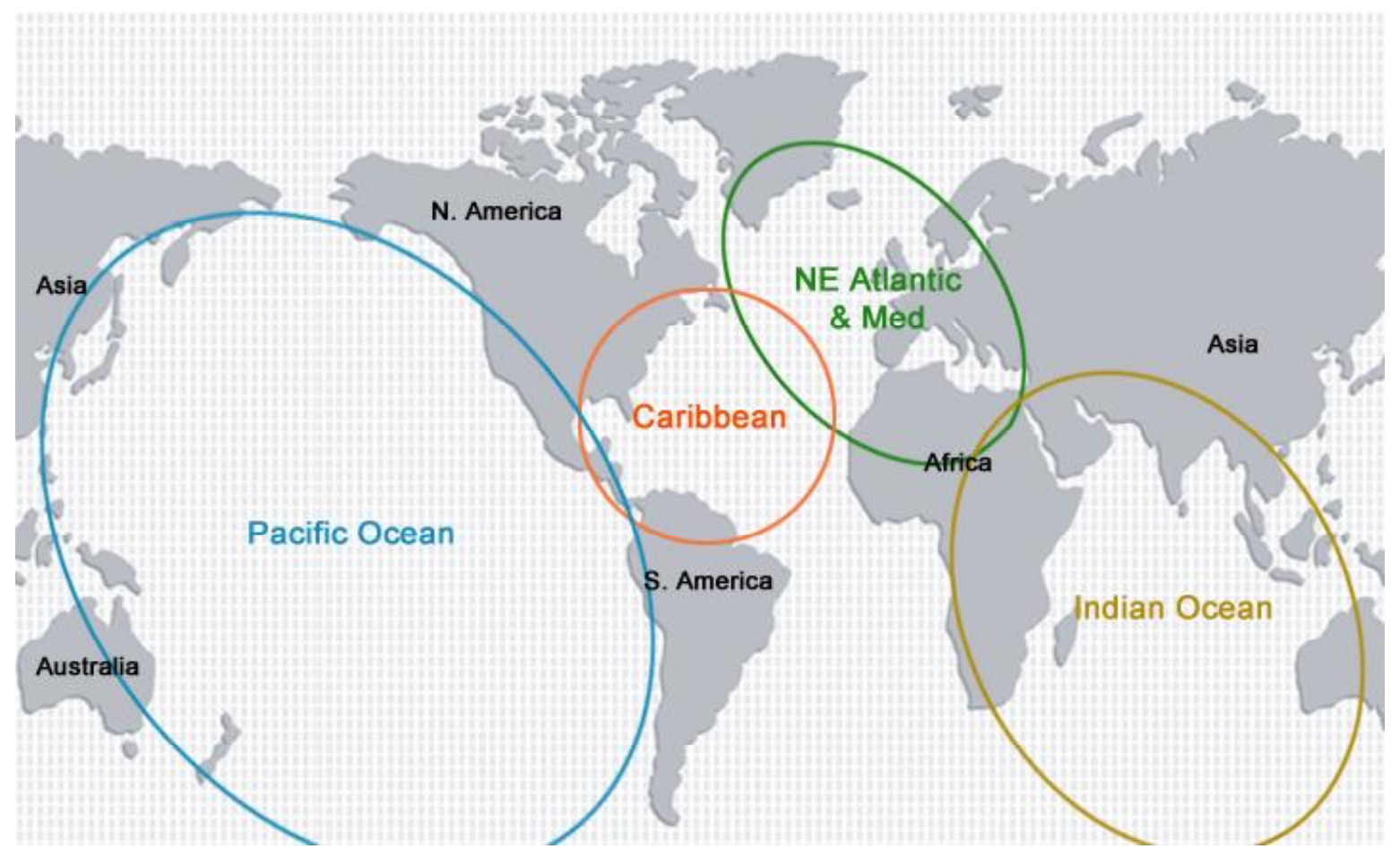

Figure 1. Regional tsunami warning systems.

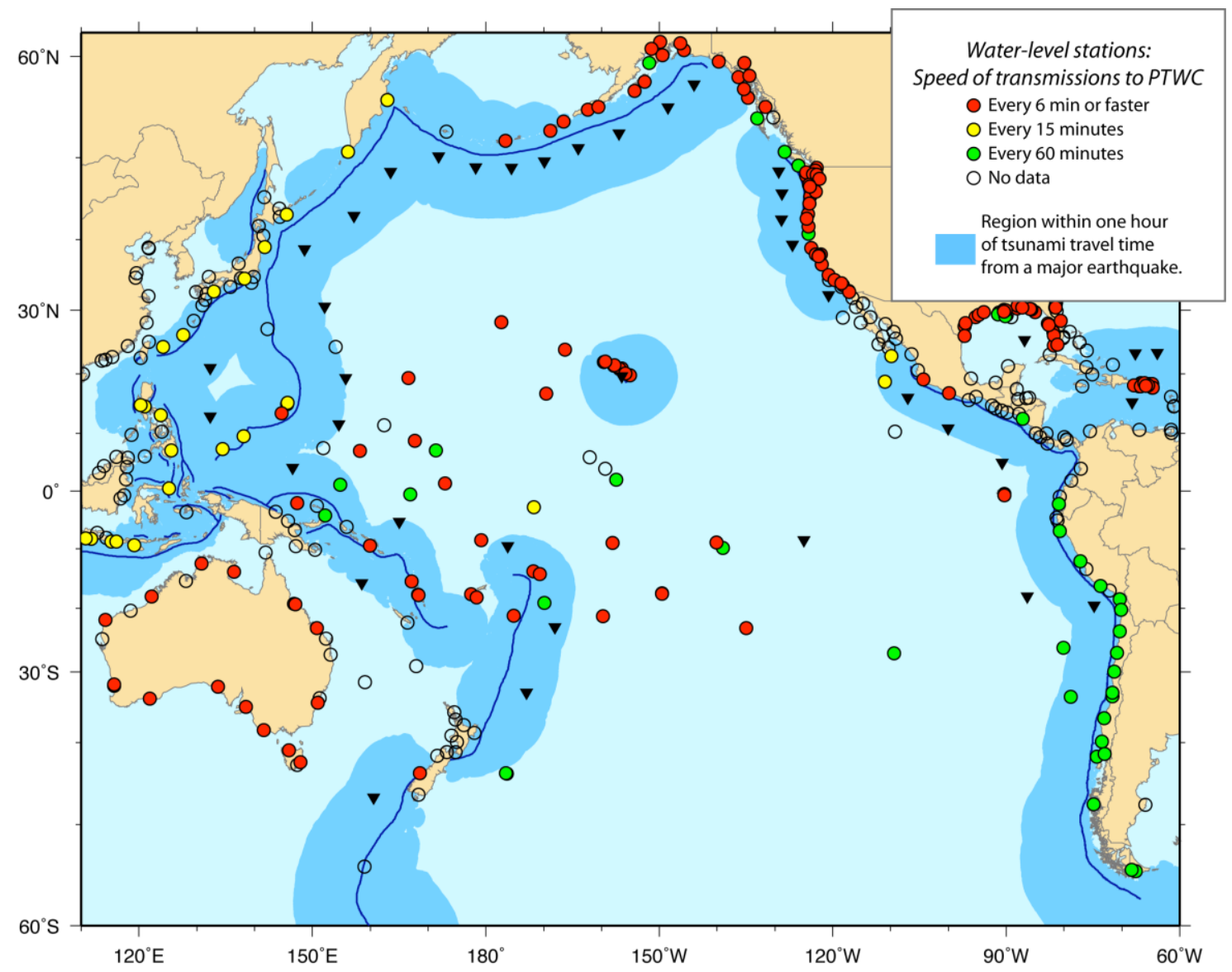

Figure 2. Tsunami monitoring in the Pacific Ocean. Circles represent coastal tide gauges and triangles represent deep ocean tsunameters with transmission times of 6 min or less (courtesy of G. Fryer, NOAA). 
(PTWC) in Hawaii and the Japan Meteorological Agency (JMA) in Tokyo.

The IOC General Assembly XXIII in Paris, 21-30 June 2005, confirmed the immediate action and response to regional Intergovernmental Coordination Groups (ICGs) for the Indian Ocean, the North-East Atlantic, and Mediterranean as well as the Caribbean. Together with the existing System for the Pacific (where a fourth ICG was subsequently established in 2006) and other relevant UN bodies they will also contribute to the work of a global Working Group on tsunami and other sealevel related hazards warning systems (TOWS).

\subsection{Pacific Ocean Region: Intergovernmental Coordination Group for the Pacific Tsunami Warning and Mitigation System (ICG/PTWS)} (Fig. 2)

The ICG/PTWS is a subsidiary body of the Intergovernmental Oceanographic Commission (IOC) of the United Nations Educational, Scientific, and predecessor (ITSU), the coordination of tsunami Cultural Organization (UNESCO). Along with its predecessor (ITSU), the coordination of tsunami warning activities in the Pacific has occurred since 1965 and currently involves 30 Pacific Member States. The ICG/PTWS acts to coordinate both international tsunami warning and mitigation activities, including the issuance of timely understandable warnings in the Pacific. Comprehensive tsunami mitigation programs require complementary and sustained activities in tsunami hazard risk assessment, tsunami warning and emergency response, and preparedness. Stakeholder involvement and coordination is essential, and community-based, people-centered mitigation activities will help to build tsunami resiliency.

Figure 2 shows that the network of deep-ocean and coastal sea level stations in the Pacific Ocean more or less provides adequate spatial coverage for sea level information to be provided within 1 hour from most tsunamigenic subduction zones in the region. Unfortunately, the data are not always provided at the required transmission frequencies to be utilized in a timely way by tsunami warning centers. Efforts are occurring to ensure all data are transmitted at required frequencies $(<6 \mathrm{~min}$ within 1 hour of subduction zone and $<15 \mathrm{~min}$ elsewhere). Details of the plan are provided in the PTWS [8].
2.2 Indian Ocean Region: The Intergovernmental Coordination Group for the Indian Ocean Tsunami Warning and Mitigation System (ICG/IOTWS) (Fig. 3)

ICG/IOTWS was formed in response to the tragic tsunami on 26 December 2004, in which over 230,000 lives were lost around the Indian Ocean region. The Intergovernmental Oceanographic Commission of UNESCO (IOC-UNESCO) received a mandate from the international community to coordinate the establishment of the system during the course of several international and regional meetings, including the World Conference on Disaster Reduction (Kobe, Japan, 18-22 January 2005), and the Phuket Ministerial Meeting on Regional Cooperation on Tsunami Early Warning Arrangements (Phuket, Thailand, 28 and 29 January 2005). The IOC Assembly, during its twenty-third Session (21-30 June 2005), formally established the ICG/IOTWS through Resolution IOC-XXIII-12. Since that time, the Intergovernmental Coordination Group has met regularly to establish and implement working plans in the Indian Ocean.

UNESCO's immediate response included an interim tsunami advisory information system in place under the aegis of the IOC of UNESCO, in cooperation with the Pacific Tsunami Warning Center (PTWC) from the USA and the Japan Meteorological Agency (JMA) from Japan, as of 1 April 2005.

All participating countries receive international tsunami advisories from the Pacific Tsunami Warning Center (PTWC) and the Japan Meteorological Agency (JMA), except Somalia. Most countries now have at least designated National Tsunami Warning Focal Points (NTWFPs), which receive these advisories at facilities that operate 24 hours a day, 7 days a week with back-up systems for receiving warning messages. Some countries such as India, Indonesia, and Australia have developed and implemented their own national tsunami warning capability and are looking to provide a coordinated Regional Tsunami Watch Provider (RTWP) service to the Indian Ocean in place of the interim tsunami advisories by 2010 .

While Fig. 3 shows the IOTWS reporting frequencies to be generally $<15 \mathrm{~min}$, many observations within 1 hour travel time from subduction zones are not transmitting at the required $<6 \mathrm{~min}$. Real-time observations are also 


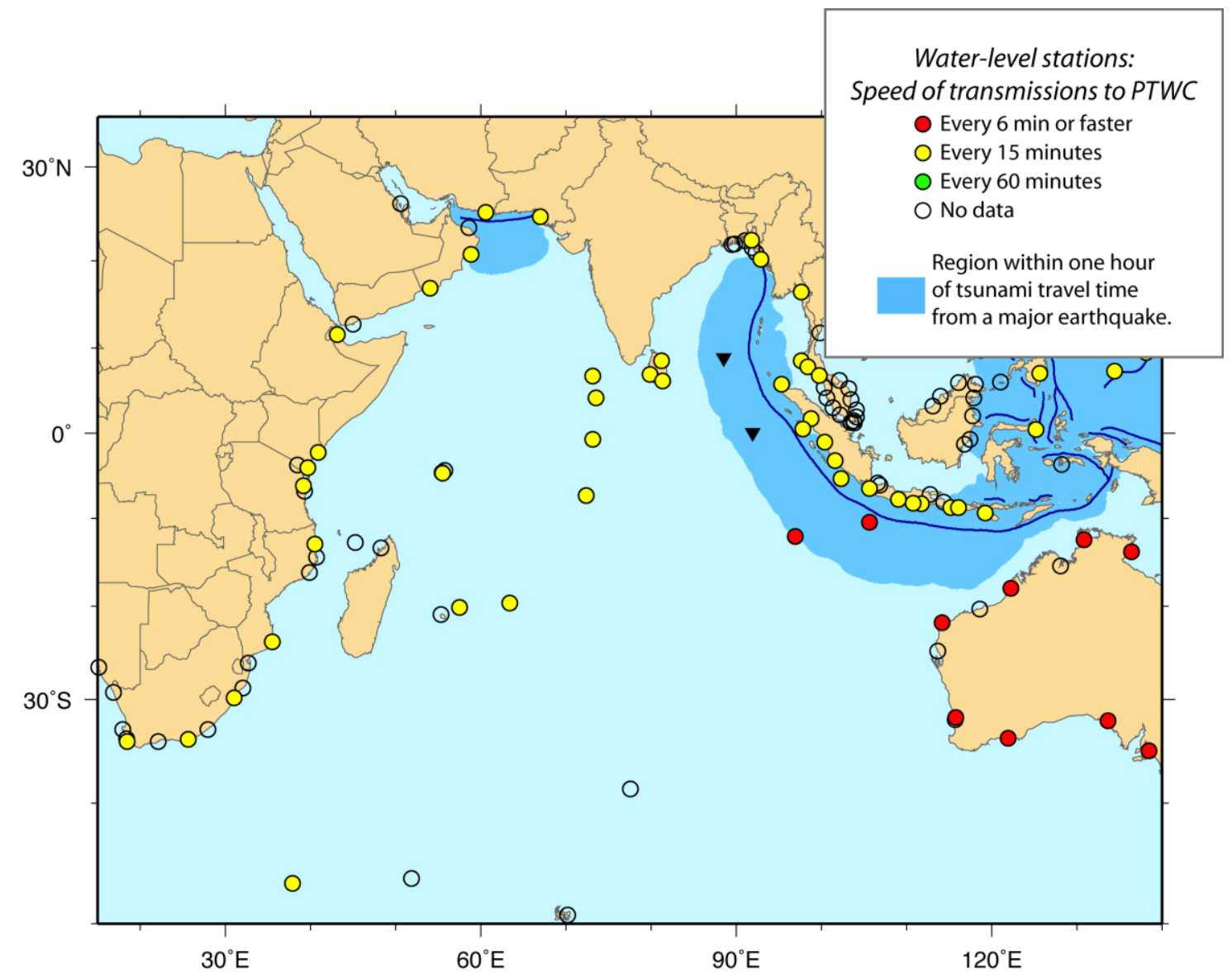

Figure 3. Tsunami monitoring in the Indian Ocean. Circles represent coastal tide gauges and triangles represent deep ocean tsunameters with transmission times of 6 min or less (courtesy of G. Fryer, NOAA).

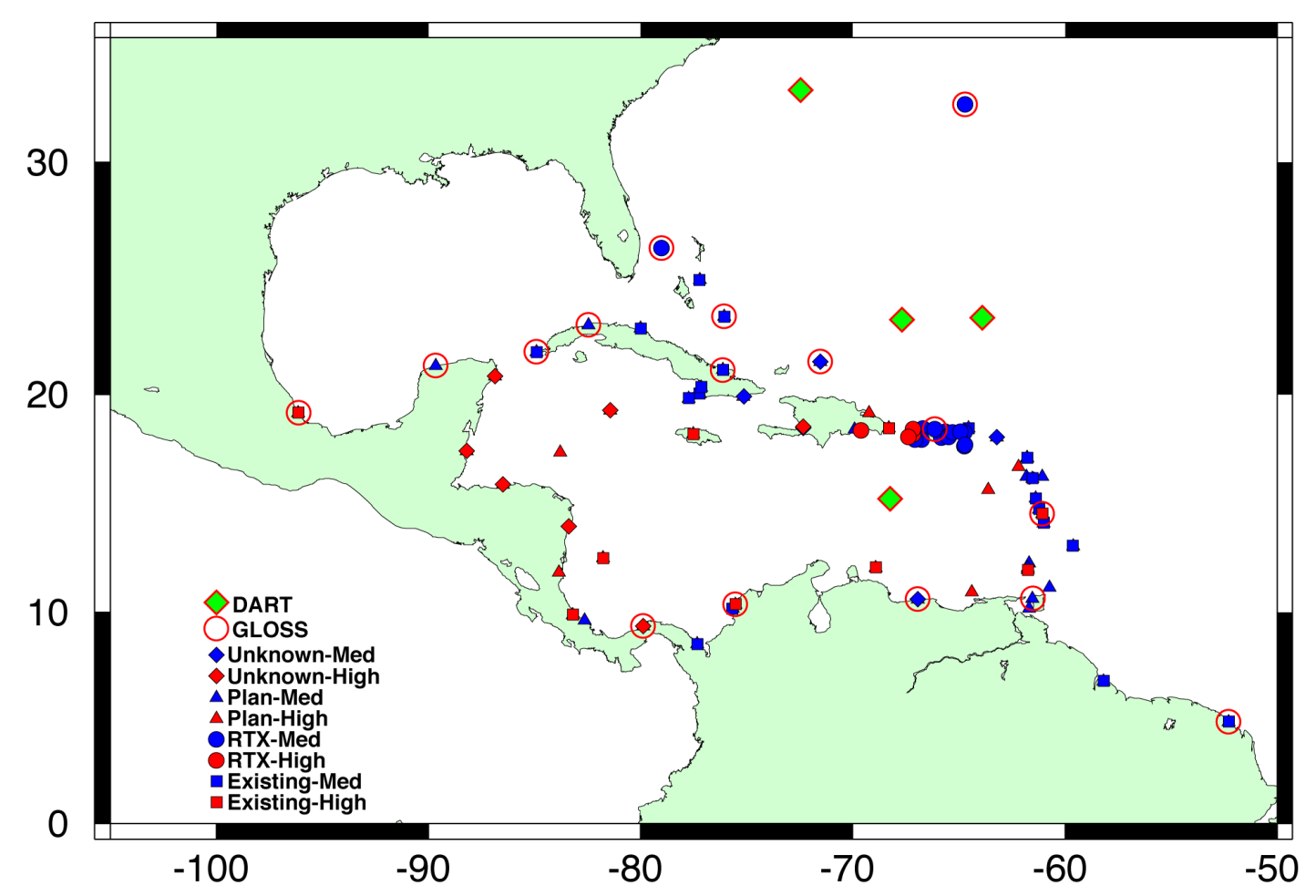

Figure 4. Existing and planned sea level stations, including coastal gauges and tsunameters for the CARIBE EWS. 
missing from some key locations. The expansion of the tsunameter network into the Indian Ocean is progressing slowly, with many more stations planned but not yet implemented. Some stations have been implemented, but the data not yet available in real time. Complete details of the implementation plan are contained in IOC report IOTWS [9].

\subsection{Caribbean Sea Region: Intergovernmental Coordination Group for the Tsunami and other Coastal Hazards Warning System for the Caribbean Sea and Adjacent Regions (ICG CARIBE EWS) (Fig. 4)}

The Caribbean region has experienced over 90 tsunamis over the past 500 years, causing at least 4562 deaths (NOAA National Geophysical Online Data Base). The primary source of these tsunamis have been local earthquakes and, to a lesser degree, volcanic eruptions, regional earthquakes and distant transatlantic events. Another potential source of tsunamis in the region is submarine landslides. Therefore, there is very little lead time for forecasts, as the tsunamis can arrive within minutes of the source event. For events within the region the maximum travel times are less than 3 hours, while transatlantic events like that of 1755 can take up to 8-9 hours.

Although there had been efforts under IOC-IOCARIBE since the mid 1990s to establish a tsunami warning system for the Caribbean, it was not until after the tragic 26 December 2004 Indian Ocean Tsunami that the Intergovernmental Coordination Group for the Tsunami and other Coastal Hazards Warning System for the Caribbean Sea and Adjacent Regions (ICG/CARIBE EWS) was established. The efforts of the ICG/CARIBE EWS are focused towards improved monitoring and detection systems and warning guidance, hazard assessment, better communications, and increased preparedness, readiness, and resilience. The Caribbean system has a multi-hazard approach and focuses on all coastal hazards.

The current operational goal of the UNESCO IOC ICG/CARIBE EWS is for tsunami products to be issued within $5 \mathrm{~min}$ of an earthquake. To achieve this, reliable earthquake and tsunami data are required. Currently data from over 100 seismic stations from the Caribbean and adjacent regions are freely available in real time and earthquakes of magnitude 4.5 or greater can be detected and located within $1 \mathrm{~min}$ for most of the region. Nevertheless, there are only 19 sea level stations contributing data and 7 operational tsunameters in the Caribbean and adjacent regions. Most of all the coastal sea level stations are concentrated in the Puerto Rico and Virgin Islands region, leaving a significant gap in sea level observations in the rest of the region. An additional 81 existing or potential sea level coastal gauges have been identified as part of the core sea level network (Fig. 4) and plans are underway to make them operational. The distribution of these stations is based on the impact of historical tsunamis, population centers, location of active volcanoes, faults, and potential submarine landslides and the GLOSS networks [10, 11, 6]. This core network of stations includes the GLOSS stations in the region as well as those identified by IOCARIBE GOOS. With all these stations the Caribbean will be in a privileged position not only to detect and monitor tsunamis, but also other coastal hazards.

Presently, the tsunami products are issued based solely on earthquake information. Sea level data are used to confirm the generation of tsunamis and the corresponding travel times and heights. NOAA inundation models have been run for four communities in Puerto Rico to identify tsunami hazard zones. For these models only source zones that could have a regional impact were considered. These source zones are located along the North America and Caribbean plate boundary zone and along the southeastern coast of Central America. But given the short travel times for the most of the earthquake scenarios, the forecasts will take longer to produce than it takes for the first tsunami wave to arrive at the coastal localities. Therefore, the forecasts derived from the deep-ocean sea level observations and the coastal sea level stations will be used to guide emergency response for later tsunami waves. Recovery efforts will be based on improved understanding of tsunami hazards in the Caribbean.

The centers that are providing tsunami products for the Caribbean are the Puerto Rico Seismic Network and the West Coast Alaska Tsunami Warning Center for Puerto Rico and Virgin Islands and the Pacific Tsunami Warning Center for the remaining Caribbean. The education and preparedness of the people and the governments in the region are critical for tsunami resiliency, especially due to the very short lead time for these events. To strengthen these efforts with the support of UNESCO and the Government of Italy, a Caribbean Tsunami Information Center is to be established in Barbados. Details of the implementation plan are in [12].

2.4 Atlantic Ocean and Mediterranean Sea Region: Intergovernmental Coordination Group for the NE Atlantic and Mediterranean Tsunami Warning and Mitigation System (ICG/NEAMTWS) (Fig. 5)

The Intergovernmental Coordination Group for the NE Atlantic and Mediterranean Tsunami Warning and. 


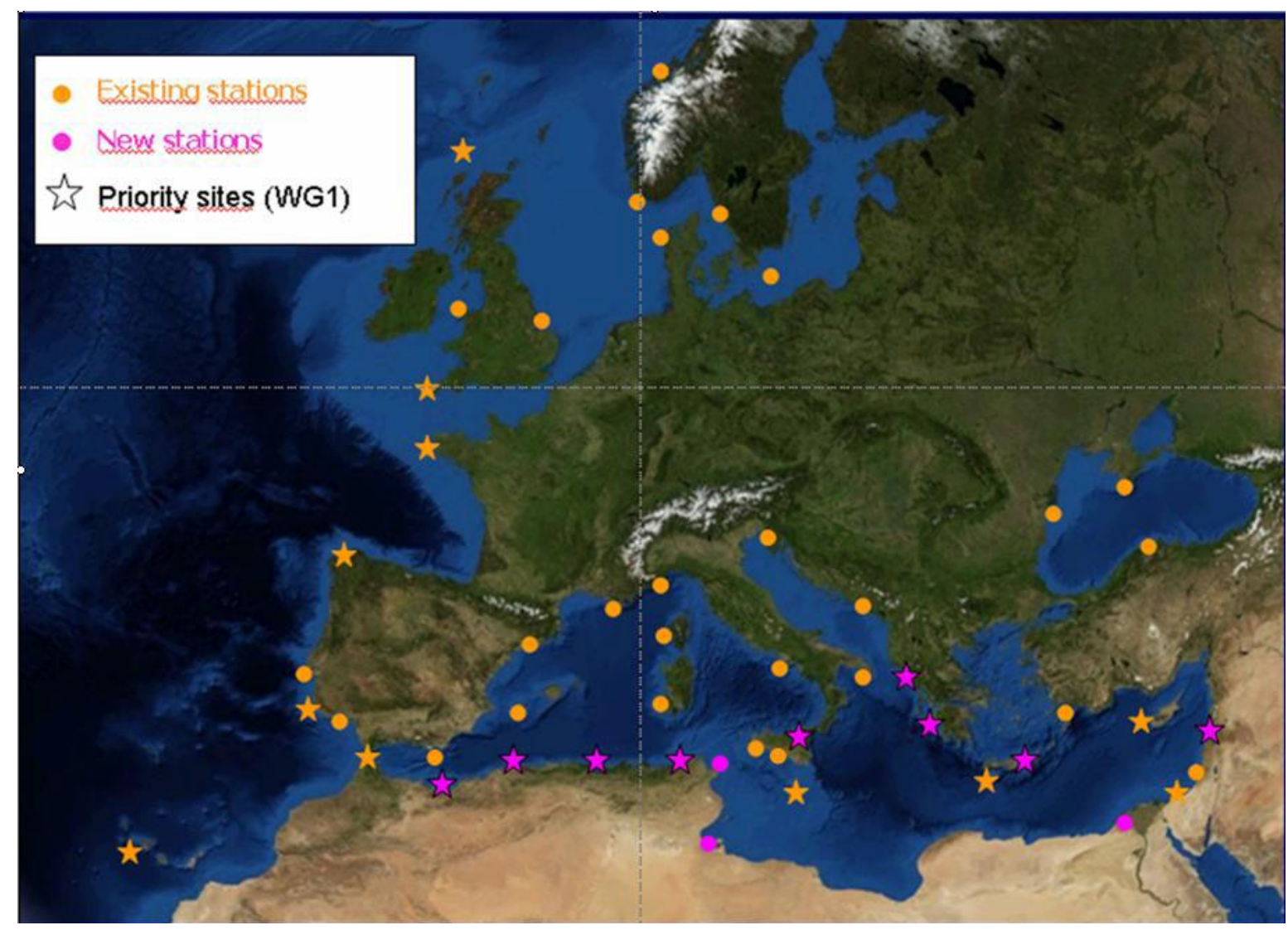

Figure 5. Status of the stations to be part of the system during NEAMTWS III. Priority sites were defined by WGI for the initial system, according to risk of tsunami.

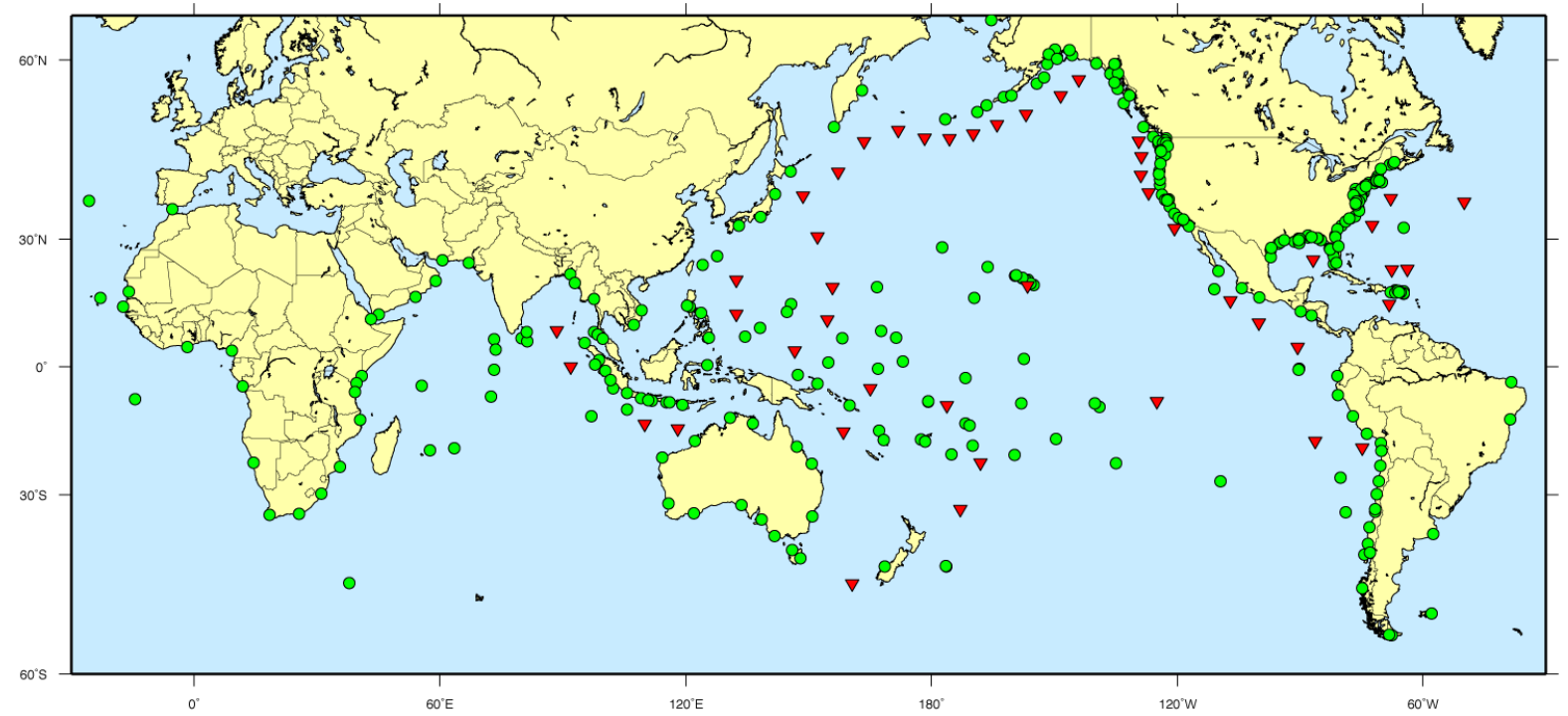

Figure 6. Global tsunami monitoring. Green circles represent coastal tide gauges and red triangles represent deep ocean tsunameters with transmission times of 6 min or less (Courtesy of G. Fryer, NOAA). 
Mitigation System (ICG/NEAMTWS) was also formed in response to the tragic tsunami on 26 December 2004.

The IOC Assembly, during its twenty-third Session (2130 June 2005), formally established the ICG/NEAMTWS through Resolution IOC-XXIII-14. In Fig. 5, locations of existing and planned coastal sealevel stations are identified to be part of the regional tsunami warning system. The Intergovernmental Coordination Group meets regularly to implement working plans in the NEAM region as detailed in [13].

\subsection{Global Working Group on Tsunamis and Other Hazards Related to Sea-Level Warning and Mitigation Systems (TOWS-WG) (Fig. 6)}

The IOC is tasked with coordinating the four tsunami warning and mitigation systems through the respective ICGs and with other international agencies and organizations. Currently, the global warning and mitigation system does not constitute a global system of systems where the regional parts can work in harmony together to serve all the needs of Member States.

The development of these TWSs derives from a strategy based on a basin-focused approach, in relation with the communities at risk and accounting for regional characteristics. It acknowledges unique oceanographic, geophysical, technical, educational, cultural, and political interests. It can also identify and strengthen national systems and existing intergovernmental capacities available for integration into an end-to-end hazard warning and mitigation system.

The relevance of the TOWS-WG was in defining the conceptual framework for integration and guiding the long-term assessment of future requirements serving Member States and organizations. Future needs drive present-day strategic investments for operations, development, and research, and promote collaboration on priorities and common objectives. The proposed framework will be dynamic and evolve to bridge crosscutting perspectives of the ICGs and align actions and performance with measured results. This TOWS-WG framework is strategic, discouraging proliferation of too many activities, with limited resources, by promoting near-term opportunities, analysis of system attributes and alternatives, and optimizes mobilization of resources for sustainable advisory and command structures.

All regional tsunami warning and mitigation systems require technical and secretariat support from IOC, other intergovernmental bodies, member states, and local organizations. There exists a risk that a proliferation of diverging interests might make the system of systems less efficient.
This does not mean that only one organizational body or one worldwide warning center is needed to do the job, even if that were possible from a purely technical point of view. Other factors that play a critical role are national and local ownership, pre-existing regional constituencies, competition among stakeholders, capacitybuilding initiatives, and overlapping responsibilities.

Starting from the individual problem of the tsunamis, each ICG has to work only on the configuration of the system adapted to its region, and to coordinate its implementation with the other regions. The ICG is therefore the authority defining the various elements of the system (observation, telecommunications, and warnings). These specifications will have then to be analyzed to identify what is specific and what can be entrusted to existing groups. It is at this level that the TOWS-WG intervenes, to propose the guidelines and ensure consistency wherever feasible in areas such as data collection and exchange and warning terminologies. The TOWS-WG will provide standards, develop common procedures and processes, and include existing competent groups [14]. WMO Congress noted and supported ongoing priority areas identified by JCOMM, including support for marine multi-hazard warning systems, within the context of the WMO priority area of disaster prevention and mitigation. Congress recognized that many of these areas could only be implemented through full and active cooperation and coordination between WMO and IOC.

\section{EVALUATION OF EXISTING OBSER- VATIONS THAT CONTRIBUTE TO TSUNAMI FORECASTING}

Each regional tsunami warning system has active working groups to implement plans agreed upon by the regional members. The implementation plans identify the requirements of tsunameter and tide gauge networks for tsunami detection and warning in each region and lay out a plan for implementing these stations. An example of this process is illustrated by the Indian Ocean region, where the network of coastal sea level stations is designed to minimize the time required to at least verify tsunami generation in regions close to the main tsunamigenic subduction zones. They are also used to monitor tsunami propagation across the Indian Ocean at strategic locations on islands and along the coastlines of mainland countries. The PTWS adopted the same principles in a joint workshop with the IOTWS in May 2006.

Care must be taken in interpreting coastal sea level data, as the signal may only represent the local response rather than offshore tsunami wave characteristics, hence the requirement and implementation of far deeper ocean tsunameters in recent years. 
Coastal sea level station characteristics include:

\section{Required sampling:}

- 1-min averages with 15-min reporting frequency in general

- 15-sec averages and 5-min reporting cycle for basinwide selected sites

- 15-sec averages and 1-min reporting cycle for selected sites within $100 \mathrm{~km}$ from the tsunamigenic source region

- Elapsed time from earthquake to tsunami detection $<1$ hour; elapsed time from earthquake to stable tsunami evaluation $<2$ hours

\section{Communication:}

- Real-time/near real-time reporting

- Dedicated communication link

- Data shared on GTS

- Ability to interrogate station is desirable

Formats:

- $\quad$ Standard format for transmission on the GTS, so that data can be directly read by standard processing tools

- RTWP data/information products-XML, CAP, etc.

Data Quality and Analysis:

- Real-time quality control procedures

- Tidal harmonic constituents for particular station locations for detiding and isolation of tsunami signals

\section{Redundancies:}

- $\quad$ Sensors, power, communication

Deep-ocean tsunami detection buoys, tsunameters, provide the best information on open-ocean tsunami wave characteristics, as the signal has not been conditioned by shallow water bathymetry. The tsunameter sea level information is therefore the most appropriate information for comparison to, or assimilation in, numerical tsunami models to forecast wave heights and basin-wide propagation characteristics.

Tsunameter station characteristics include:

\section{Required Sampling:}

- 15-min samples with 6-hour or less reporting frequency in normal mode
- $>$ or equal to 1-min averages with <5-min reporting frequency in event mode, once triggered

- Trigger thresholds and activation protocols need agreement between RTWPs and NTWCs/tsunameter operators

\section{Communication:}

- Normal mode/event mode reporting

- Appropriate satellite communications links

- Data shared on GTS

- Two-way communications for manual triggering and system status checks

- Reporting delay from seafloor $<3 \mathrm{~min}$

Formats:

- - Standard format for transmission to GTS

Data Quality and Analysis:

- Real-time quality control procedures

- Procedures for capturing tsunameter data, analyzing it, and processing and evaluating the tsunami signal in an appropriate modeling environment.

\section{Redundancies:}

- Power and communication in surface buoy

\section{ACTIONS TO SUSTAIN AND IMPROVE TSUNAMI OBSERVATIONS AND FORECASTS}

The existing structure of regional coordinating groups should be supported by each member nation. Empowering the regions that utilize global guidelines would ensure that regional interests are served while enabling each region to successfully interact with other regions. Regional tsunami warning systems will benefit from adhering to global guidelines and the advantages of standard hardware, software, and procedures being available and adopted. It is important to realize that our global society is very mobile and tourism represents a major economic activity along the world's beaches. Common global procedures will decrease the risk to residents as well as tourists from future tsunami dangers.

Wherever possible, sea level monitoring stations should support observations required for multi-hazards. This facilitates and enhances justification for their ongoing support and maintenance, often leading to economies of scale and funding support. The TOWS WG has requested that JCOMM review the terms of reference and membership of GLOSS to formally include support for implementation of coastal sea level observing networks that also support tsunami monitoring and warning activities (requirements identified by tsunami 


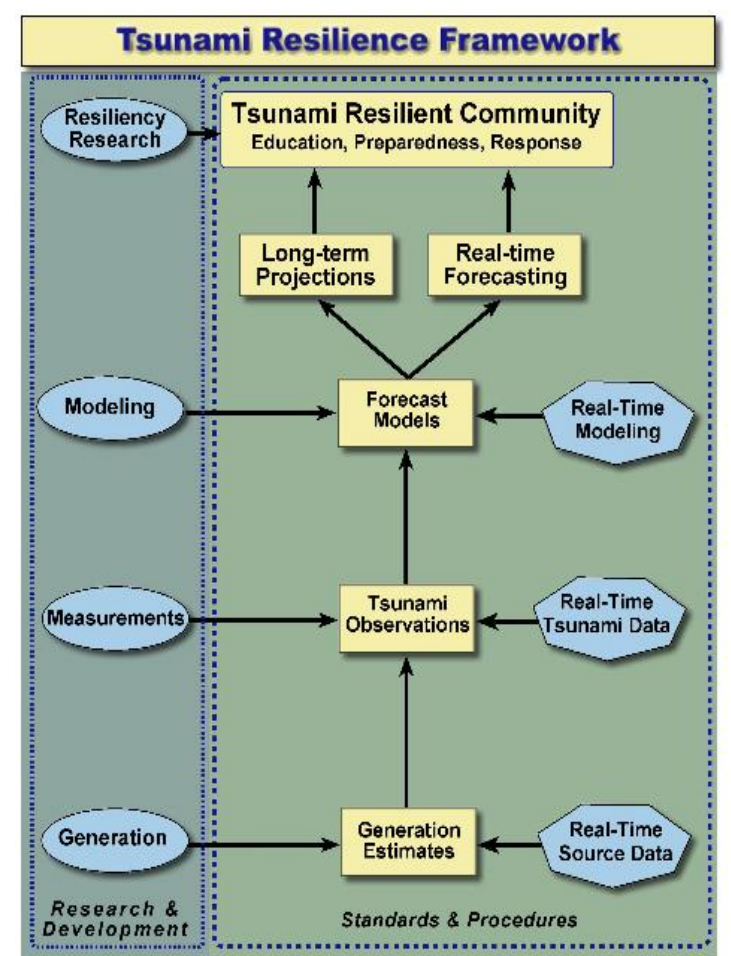

Figure 7. Concept of a Tsunami Forecasting

Framework that contributes to resilience

through standard operational procedures and is updated/upgraded through research.

warning centers and the respective ICGs). While multipurpose sea level monitoring stations may be ideal, sea level stations implemented for climate monitoring are not always ideally located for tsunami monitoring (and vice versa). Similarly, TOWS has requested that JCOMM review the terms of reference and membership of the Data Buoy Cooperation Panel (DBCP) and consider a merger with the ITP to further coordinate and integrate respective deep-ocean platform activities. An unexpected challenge has arisen involving the malicious vandalism of deep-ocean buoys that affect the cost and effort to detect tsunamis in real time. Efforts to stem this expensive practice have included education programs, editorials in newspapers, and engineering efforts to make vandalism more difficult.

\subsection{Tsunami Forecasting as a Unifying Framework (Fig. 7)}

Since the watershed 2004 tsunami, new data and ideas are entering the scientific literature at a pace unprecedented in the history of tsunami science. Two of the most seminal advances in tsunami research, since the Indian Ocean tsunami, are (i) deep-ocean tsunami measurements/monitoring and (ii) their use in accurately forecasting tsunamis after the tsunami has been generated. Using direct measurements of tsunamis greatly improves the real-time forecast accuracy over earthquake-derived magnitude estimates of tsunami intensity. These same forecast models can also be used to determine potential tsunami scenarios (using scientifically credible tsunami generation sources) to prepare inundation and evacuation maps for coastal communities, and other consequence assessment tools. To create a tsunami-resilient community, three activities are required: 1) an assessment of the tsunami hazard for each threatened community, 2) an appropriate mitigation strategy to minimize the impact of future tsunamis, and 3) an effective warning and education program to alert the at-risk populations. One integrating principle that could be used to organize our future efforts is tsunami forecasting. A tsunami forecast system, as described above, could serve as an operational system that integrates the state-of-thescience for tsunami generation, propagation, and inundation (see Fig. 7).

\subsection{Tsunami Modeling Technology}

The tsunami forecast modeling shown in Fig. 7 illustrates the use of operational models for real-time tsunami forecasting and long-term tsunami projections used in hazard planning. Also shown on the left side of Fig. 7 is the scientific opportunity to conduct research to improve models or as a scientific resource to use in other research fields. In the research mode, scientists can use the forecast model as a standard model to improve new dynamical processes or numerical methods. Once the new research has produced a model to compare with the standard model, then the impact of the new research can be quantified during the next tsunami. Using the forecasting framework can promote the development AND ACCEPTANCE of new modeling technology. In the user mode, a researcher does not need to be a modeling expert to conduct research on new applications of the modeling technology. For example, if an oceanographer wanted to monitor currents in a harbor, the researcher might want to know the range of currents possible. By using the forecast model in a scenario mode, estimates of tsunami-induced currents could be derived easily without spending years developing an accurate hydrodynamic model. Similarly, a social scientist may want to use these models to design an evacuation plan for a community. By establishing and maintaining a set of standardized tsunami forecast models, the larger scientific community benefits.

\subsection{Tsunami Measurement Technology}

The tsunami forecast observations shown in Fig. 7 illustrates the use of operational measurements for realtime tsunami forecasting and basic research. Placing measurements in the context of a forecast system gives rise to many scientific opportunities. One set of practical 
questions involve the cost of establishing and maintaining the observational systems. The forecast system framework allows for array design research that optimizes the forecast accuracy with minimal observations. Or, the framework could answer questions about combining tsunami observations with other oceanographic programs to minimize costs to all contributing programs. Another set of research questions is how to measure tsunamis in the deep ocean and in coastal areas as well as how to measure the time evolution of flooding. Measurements are a necessary part of model validation as well as original research to formulate new hypotheses. Progress in developing building codes in tsunami hazard areas, for example, is restricted due to the lack of measurements of forces on structures, forces of objects carried along with flooding (debris), and the time evolution of multiple flooding waves. Research on every new tsunami brings more questions than answers, so the field of tsunami measurements is wide open for new discoveries by creative observational scientists. Using the forecasting framework can promote the development AND ACCEPTANCE of new measurement technologies.

\section{FUTURE CHALLENGES FOR COMMUNITY RESILIENCE}

To support regional coordinating groups requires a proactive tsunami response and recovery plan process including:

\subsection{Establish a Team to Develop a Tsunami Response and Recovery Plan}

Because tsunamis are inherently international, existing IOC-endorsed tsunami organizations at the global and regional levels need to be supported by national advocate teams. The advocacy team must seek to coordinate the national programs with the regional and global programs to maximize the impact of a national tsunami preparedness program. Ideally, the national advocacy team will have representation from the national government and provincial, district, and local jurisdictions to coordinate planning, response, and recovery activities. It is critical that the local member serve as the community advocate for preparedness. One planning activity that could help establish and maintain the team is to produce a Tsunami Response and Recovery Plan. This exercise will identify all the links from the national government to the local community to implement an appropriate tsunami response and preparedness within the community, as well as should a community be damaged by the next tsunami. Following a tsunami, there is an overwhelming willingness to help. But, a problem arises in trying to direct the help to the right people under disastrous conditions.
A well-thought-out recovery plan will alleviate much of the confusion and suffering following the tsunami. At the same time, the team will gel as it identifies problems in directing resources to help the local community. Such a plan needs to be developed within a national multihazard framework.

\subsection{Every Tsunami is an Opportunity to Update the Tsunami Response and Recovery Plan}

As the advocacy team develops their tsunami recovery plan, they will inevitably find problems with the existing structure. One way to overcome such obstacles is to capitalize on every tsunami, regardless of origin, to address the deficiencies of the recovery plan. These tsunamis also allow a teaching moment to better prepare the nation for the next tsunami. Media coverage of the tsunami and linkages to the recovery plan will educate the public on the advocacy team's efforts. Editorials can be written to highlight the strengths and weaknesses of the plans. Each tsunami is also an opportunity to train national scientists and emergency managers by supporting teams to investigate the details of the tsunami's impact. The survey and evaluation teams will bring home valuable lessons learned by the impacted communities to avoid similar mistakes.

\subsection{Regularly Review the Tsunami Response and Recovery Plan}

A response and recovery plan is not a static document. All levels of governments and jurisdictions will constantly change, so a process must be implemented to adjust the response and recovery plan to these changes. One effective quality control device is a regular review of the plan. A review will increase the team's credibility through an open public process. A review also provides input for updating the response and recovery plans, identifies and documents problems, and documents the process of change. More importantly, a review allows an opportunity for additional support and for adding new team members.

\subsection{Benefits of a Tsunami Response and Recovery Plan}

A tsunami response and recovery plan is an essential part of a community's ability to prepare for and recover from the next tsunami. Communities that expend the effort to develop an effective response and recovery plan will save lives, protect property, and the community will survive. Those communities that do not develop a response and recovery plan may not survive the next tsunami. 


\section{REFERENCES}

1. Bernard, E.N. (ed.) (2005). Developing tsunami-resilient communities: The National Tsunami Hazard Mitigation Program, Reprinted from Natural Hazards 35(1), p. 184 (Springer, The Netherlands).

2. Synolakis, C.E., Bernard, E.N., Titov, V.V., Kânoğlu, U. \& González, F.I. (2009). Validation and Verification of Tsunami Numerical Models. Pure Appl. Geophys., 165(11-12), 2197-2228.

3. Samant, L.D., Tobin, L.T. \& Tucker, B. (2007). Preparing Your Community for Tsunamis: A Guidebook for Local Advocates. GeoHazards International, $54 \mathrm{pp}$.

4. McAdoo, B.G., Dengler, L., Prasetya, G. \& Titov, V. (2006). Smong, How an Oral History Saved Thousands on Indonesian's Simeulue Island during the December 24, 2004 and March 2005 Tsunamis. Earthquake Spectra, Special Issue III, 22, S661-S670.

5. Tang, L., Titov, V.V. \& Chamberlin, C. (2009). Development, Testing, and Applications of SiteSpecific Tsunami Inundation Models for Real-Time Forecasting. J. Geophys. Res., 114, C12025, doi:10.1029/2009JC005476.

6. UNESCO (2005). The Group of Experts on the Global Sea Level Observing System (GLOSS). Ninth Session, Paris, France, 24-25 February 2005, GOOS Report No. 149, GCOS Report No. 99, JCOMM Report No. 36.

7. Merrifield, M. \& Co-Authors (2010). "The Global Sea Level Observing System (GLOSS)" in these proceedings (Vol. 2), doi:10.5270/OceanObs09.cwp.63.

8. PTWS (2009). PTWS Implementation Plan, 2009. Twenty-Third Session of the Intergovernmental Coordination Group for the Pacific Tsunami Warning and Mitigation System (ICG/PTWS-XXIII), Intergovernmental Oceanographic Commission (of UNESCO), ICG/PTWS-XXIII/12, Paris, France, 27 January 2009, 25 pp.

9. IOTWS (2008). Indian Ocean Tsunami Warning and Mitigation System (IOTWS). Implementation Plan for Regional Tsunami Watch Providers (RTWP). IOC Technical Series 81, 36 pp.

10. Henson, J., Muller-Karger, F., Wilson, D., Morey, S., Maul, G., Luther, M. \& Kranenburg, C. (2006). Strategic Geographic Positioning of Sea Level Gauges to Aid in Early Detection of Tsunamis in the IntraAmericas Sea. Science of Tsunami Hazards, 25(3), 173-207.

11. IOC (2008). IOC-GLOSS-PRSN Caribbean Training Course for Operators of Sea Level Stations. June 2327, 2008, Mayagüez, Puerto Rico.

12. CARIBE (2008). Caribe EWS Implementation Plan. Third Session of the Intergovernmental Coordination Group for the Tsunami and Other Coastal Hazards Warning System for the Caribbean and Adjacent
Regions, ICG/CARIBE EWS-III/13, Panama, 12-14 March 2008, Intergovernmental Oceanographic Commission (of UNESCO), Paris, France, 13 February 2008, 16 pp.

13. NEAMTWS (2007). North-East Atlantic, the Mediterranean and Connected Seas Tsunami Warning and Mitigation System (NEAMTWS), Implementation Plan, Version 3.2, 24 July 2007. Third Session of the Intergovernmental Coordination Group for the NorthEast Atlantic, the Mediterranean and Connected Seas Tsunami Warning and Mitigation System (NEAMTWS), IOC Technical Series No. 73, 42 pp.

14. TOWS (2009). Working Group on Tsunamis and Other Hazards Related to Sea-Level Warning and Mitigation Systems (TOWS-WG). Intergovernmental Oceanographic Commission, Second Meeting, UNESCO Headquarters, Paris, France, 27 March 2009, $31 \mathrm{pp}$. 